\title{
ACCURACY OF THE SWEAT TEST: ADVANTAGE OF A MICROMETHOD
}

\author{
BY
}

\author{
R. DE HALLER*, J. DE HALLER, and P. SIEGENTHALER $\dagger$ \\ From the Institute of Diseases of the Chest, Brompton Hospital, London, \\ and the Policlinique Universitaire de Médecine, Geneva (Switzerland)
}

(RECEIVED FOR PUBLICATION APRIL 26, 1965)

The high sweat electrolyte concentration in cystic fibrosis is most important in the diagnosis of this disease. The method used for its determination should be simple to perform, harmless to the patient, and accurate. The widely-used method of collecting sweat on a filter paper (Shwachman, Leubner, and Catzel, 1955) after pilocarpine iontophoresis (Gibson and Cooke, 1959) fulfils the first two conditions but not the latter. Both weighing and elution may introduce serious errors, and the method is known to be unreliable for samples weighing under $20 \mathrm{mg}$. Moreover, the sweat sample is not transportable and has to be analysed rapidly in order to avoid evaporation.

A simple, harmless, and accurate method of collecting and estimating sweat electrolyte concentration is described, which has given satisfactory results for over three years (de Haller, Siegenthaler, Hampaï, Spahr, Vulliet, and Favre, 1962; Siegenthaler, de Haller, de Haller, Hampaï, and Muller, 1964).

\section{Material and Methods}

The skin area (palmar aspect of the forearm in adults, or epigastrium in small children) is cleaned with distilled water and alcohol ether. Sweat secretion is stimulated by the iontophoresis of 5 drops of a $0 \cdot 2 \%$ pilocarpine nitrate solution placed on a filter paper $4 \mathrm{~cm}$. in diameter, which is covered with the positive electrode $3.5 \mathrm{~cm}$. in diameter (Gibson and Cooke, 1959). The negative electrode trapped in gauze soaked in electrolyte, is held in the patient's hand. A current of $2 \mathrm{mAmp}$. is maintained for 5 minutes. If large sweat samples are needed, they can easily be obtained by increasing the area of the electrode, the amount of pilocarpine, and the electrical intensity. After stimulation, the skin is washed with distilled water and thoroughly dried. It is then covered with a glass or plastic cup $4.5 \mathrm{~cm}$. in diameter and, in

\footnotetext{
* Research fellow 1963-1964, Institute of Diseases of the Chest, Brompton Hospital, London. Present address: Basle Sanatorium, 7260 Davos (Switzerland).

† Policlinique universitaire de médecine, Geneva (Switzerland).
}

order to avoid contact with the sweat, at least $0.5 \mathrm{~cm}$. high (the cap of a standard screw-topped bottle was used). The cup, washed with distilled water and dried, is fixed to the skin with tape, and to prevent condensation is kept at body temperature by an electric pad or a warm hand. After 20 minutes the cup is removed. If condensation has occurred in the cup, the sample should be discarded. The sweat drops are collected by drawing a capillary tube gently over the skin surface. There will be no significant evaporation if this collection takes place within 30 seconds, which is easy to achieve. By inclining the tube at an appropriate angle the sweat ascends spontaneously, and air bubbles, which would complicate sampling, are avoided. The tube is then sealed in a low flame (the pilot light of a Bunsen burner is ideal) $2 \mathrm{~cm}$. beyond the extremities of the sweat column. The tightness of the first sealing can be tested by holding the tube vertically, open end down. The capillary tube, 1-2 mm. in diameter, is made of ordinary laboratory glass, washed with chromic acid and tap water, rinsed with distilled water, and dried. For estimation, no weighing is required, as the sweat sample is then aspirated directly into a plastic micropipette (Sanz, 1957). The same pipette is used for both sweat and standard solution. This is not possible with a glass ultramicropipette (Kirk type), with which an additional error of $1-4 \%$ must be taken into account (Sanz, 1957). $5 \mu$ l. are required for one estimation of $\mathrm{Na}$ or $\mathrm{Cl}$, and $20 \mu \mathrm{l}$. for $\mathrm{K}$. $\mathrm{Na}$ and $\mathrm{K}$ are estimated by a flame photometer (Beckman), providing a direct reading after dilution with $1 \mathrm{ml}$. distilled water delivered by an automatic syringe;* chloride is estimated by a Beckman and Spinko microburette (Sanz, 1957) as titrated by Schales and Schales (1941). Only values for sodium will be reported here.

The accuracy of the method was checked with a series of $\mathrm{NaCl}$ solutions of 7 different strengths obtained by diluting a solution of approximately $120 \mathrm{mEq} / \mathrm{l}$. Na. Their exact concentration is given in the Table. The majority contained over $50 \mathrm{mEq} / \mathrm{l}$. Na, as it was more

* An identical experiment, as described below, was performed on standard solutions of $\mathrm{NaCl}$ with an Evans Electrode Photometer (Eel), as this type is more widely used. $5 \mu$ l. samples were adequately diluted with an ordinary pipette so that the values could be read on the $100 \mathrm{U}$ scale. Accuracy of the results was of a similar order to that of the original experiment. 
TABLE

ACCURACY OF CAPILLARY TUBE METHOD TESTED AGAINST 7 SOLUTIONS OF NaCl, WITH 2 TUBES (a AND b) FOR EACH SOLUTION

\begin{tabular}{|c|c|c|c|c|c|c|c|}
\hline \multirow{2}{*}{$\begin{array}{l}\text { Standard Solution } \\
(\mathrm{mEq} / \mathrm{l} . \mathrm{Na})\end{array}$} & \multirow{2}{*}{$\begin{array}{l}\text { Capillary } \\
\text { Tube }\end{array}$} & \multicolumn{5}{|c|}{$\mathrm{Na}$ Concentration (mEq/l.) } & \multirow{2}{*}{$\begin{array}{c}\text { Maximum } \\
\text { Difference } \\
\text { in Percentage } \\
\text { of Mean }\end{array}$} \\
\hline & & \multicolumn{2}{|c|}{ Dry End $_{b}$} & \multicolumn{2}{|c|}{$a{ }_{b}$ Wet End } & Mean & \\
\hline I: $118 \cdot 0$ & $\left\{\begin{array}{l}a \\
b\end{array}\right.$ & $\begin{array}{l}116 \cdot 0 \\
117 \cdot 0\end{array}$ & $\begin{array}{l}117 \cdot 0 \\
119 \cdot 0\end{array}$ & $\begin{array}{l}117 \cdot 0 \\
116 \cdot 0\end{array}$ & $\begin{array}{l}120 \cdot 0 \\
120 \cdot 0\end{array}$ & $118 \cdot 0$ & 3 \\
\hline II : $96 \cdot 5$ & $\left\{\begin{array}{l}\mathbf{a} \\
\mathbf{b}\end{array}\right.$ & $\begin{array}{l}97 \cdot 5 \\
95 \cdot 0\end{array}$ & $\begin{array}{l}96 \cdot 5 \\
96 \cdot 0\end{array}$ & $\begin{array}{l}96 \cdot 0 \\
97 \cdot 0\end{array}$ & $\begin{array}{r}100 \cdot 0 \\
97 \cdot 5\end{array}$ & $97 \cdot 0$ & 5 \\
\hline III: $81 \cdot 0$ & $\left\{\begin{array}{l}a \\
b\end{array}\right.$ & $\begin{array}{l}79 \cdot 0 \\
81 \cdot 0\end{array}$ & $\begin{array}{l}81 \cdot 0 \\
80 \cdot 0\end{array}$ & $\begin{array}{l}80 \cdot 0 \\
79 \cdot 5\end{array}$ & $\begin{array}{l}82 \cdot 0 \\
82 \cdot 0\end{array}$ & $80 \cdot 5$ & 4 \\
\hline IV: $\quad 57 \cdot 5$ & $\left\{\begin{array}{l}a \\
b\end{array}\right.$ & $\begin{array}{l}58 \cdot 0 \\
58 \cdot 0\end{array}$ & $\begin{array}{l}58 \cdot 0 \\
60 \cdot 0\end{array}$ & $\begin{array}{l}57 \cdot 0 \\
59 \cdot 5\end{array}$ & $\begin{array}{l}57 \cdot 0 \\
61 \cdot 0\end{array}$ & $58 \cdot 5$ & 7 \\
\hline$V: 48 \cdot 5$ & $\left\{\begin{array}{l}a \\
b\end{array}\right.$ & $\begin{array}{l}52 \cdot 0 \\
48 \cdot 0\end{array}$ & $\begin{array}{l}49 \cdot 0 \\
49 \cdot 0\end{array}$ & $\begin{array}{c}48 \cdot 0 \\
(42 \cdot 0)\end{array}$ & $\begin{array}{l}48 \cdot 0 \\
49 \cdot 0\end{array}$ & $49 \cdot 0$ & 8 \\
\hline VI: $\quad 16 \cdot 0$ & $\left\{\begin{array}{l}\mathrm{a} \\
\mathrm{b}\end{array}\right.$ & $\begin{array}{l}16 \cdot 0 \\
16 \cdot 5\end{array}$ & $\begin{array}{l}16 \cdot 0 \\
17 \cdot 5\end{array}$ & $\begin{array}{l}16 \cdot 0 \\
16 \cdot 0\end{array}$ & $\begin{array}{l}16 \cdot 5 \\
16 \cdot 0\end{array}$ & $16 \cdot 5$ & 9 \\
\hline VII: $8 \cdot 0$ & $\left\{\begin{array}{l}\mathrm{a} \\
\mathrm{b}\end{array}\right.$ & $\begin{array}{l}8 \cdot 0 \\
8 \cdot 0\end{array}$ & $\begin{array}{l}8 \cdot 0 \\
8 \cdot 0\end{array}$ & $\begin{array}{l}7 \cdot 5 \\
7 \cdot 5\end{array}$ & $\begin{array}{l}7 \cdot 5 \\
8 \cdot 0\end{array}$ & $8 \cdot 0$ & 6 \\
\hline \multicolumn{2}{|c|}{ Mean (solutions I-V) } & \multicolumn{2}{|c|}{$80 \cdot 43 \pm 1 \cdot 23$} & \multicolumn{2}{|c|}{$80 \cdot 38 \pm 2 \cdot 50$} & & \\
\hline
\end{tabular}

Note: The values have been rounded up to the nearest half unit. Statistical calculations were applied only to solutions I-V.

important to assess the accuracy of the method in borderline and pathological values (upper limit of the normal $=$ 70-80 mEq/l. Na). Two capillary tubes ( $a$ and $b$ ) were filled with each solution and sealed, and 4 estimations were performed for each tube: the first two from the end which was wetted when drawing up the solution, the second two from the dry end. This was done to ensure that higher concentrations of sodium did not occur in the wetted end as a result of evaporation during sealing (Table).

\section{Results and Discussion}

In columns 3 and 4 of the Table the results of the double estimations made at the dry end of each capillary tube are listed, and in columns 5 and 6 those made at the wet end. The respective mean values are not significantly different (difference of the means $=0.05 \pm 2.40$ ), even though the standard deviation of the mean value at the wet end is larger than that found at the dry one. This means that by sealing the capillary tube $2 \mathrm{~cm}$. beyond the sweat column, the minute evaporation that may occur at the wet end has no significant effect on the final result. Closing the tube with plasticine failed to give satisfactory results, as this substance loses its plastic properties with drying or cooling. Once sealed, the tube can be transported and stored for weeks, the electrolyte concentration of the sweat remaining unaltered. This is valuable for paediatricians living far away from laboratory centres.

Column 8 shows that below $50 \mathrm{mEq} / \mathrm{l}$. $\mathrm{Na}$ the maximum experimental error of this method is $9 \%$ (the single incidental extreme value of $42 \mathrm{mEq} / \mathrm{l}$. in solution $\mathrm{V}$ not being taken into account), and that above $50 \mathrm{mEq} / \mathrm{l}$. it does not exceed $7 \%$.
In contrast, paediatricians find the error of occasional sweat tests with the filter paper method to be $\pm 15 \%$; in trained hands the maximum error remains as much as $\pm 10 \%$, reaching $\pm 25 \%$ when samples are minute or poorly concentrated (Lobeck and Huebner, 1962). With the capillary tube method, the electrolyte concentration of small amounts of sweat can be estimated accurately. This is valuable for the study of sweat physiology (Siegenthaler et al., 1964), and is very useful in small children whose sweat production may be limited.

In addition to its accuracy, the capillary tube method has the advantage that it uses techniques and apparatus available in most routine laboratories. This is not the case with other methods suggested recently, which have been based on electrical conductivity of sweat, using conductivity cells (Shwachman, Dunham, and Phillips, 1963) and sodium electrodes (Goldbloom and Sekelj, 1963), the accuracy of which, moreover, is not better than that of the filter paper.

In conclusion the capillary tube method is simple to perform and provides accurate results, even for minute amounts of sweat. As the capillary tube is sealed after collection, it may be transported and stored. For estimation of sodium and other sweat electrolytes ordinary laboratory equipment is suitable.

\section{Summary}

A new capillary tube method is described for the analysis of sodium and other electrolytes in sweat. This is shown to be reliable and more accurate than other methods. Furthermore, standard laboratory 
equipment can be used, and the capillary tube containing the sweat sample can be sealed, transported, and stored.

We wish to thank Mr. P. M. Payne, director of the South Metropolitan Cancer Registry, Sutton (Surrey), for the statistical investigation, and Dr. D. G. Jones and Dr. J. C. Batten of the Brompton Hospital for their help.

\section{REFERENCES}

Gibson, L. E., and Cooke, R. E. (1959). A test for concentration of electrolytes in sweat in cystic fibrosis of the pancreas utilizing pilocarpine by iontophoresis. Pediatrics, 23, 545.

Goldbloom, R. B., and Sekelj, P. (1963). Cystic fibrosis of the pancreas: diagnosis by application of a sodium electrode to the skin. New Engl. J. Med., 269, 1349.

de Haller, R., Siegenthaler, P., Hampaï, A., Spahr, A., Vulliet, V., and
Favre, R. (1962). Étude critique du test de la transpiration pour le dépistage des hétérozygotes de la mucoviscidose. Schweiz. med. Wschr., 92, 1493.

Lobeck, C. C., and Huebner, D. (1962). Effect of age, sex, and cystic fibrosis on the sodium and potassium content of human sweat. Pediatrics, 30, 172

Sanz, M. C. (1957). Ultramicro methods and standardization of equipment. Clin. Chem., 3, 406.

Schales, O., and Schales, S. S. (1941). A simple and accurate method for the determination of chloride in biological fluids. J. biol. Chem., 140, 879.

Shwachman, H., Dunham, R., and Phillips, W. R. (1963). Electrical conductivity of sweat. A simple diagnostic test in children. Pediatrics, 32, 85.

- Leubner, H., and Catzel, P. (1955). Mucoviscidosis. Advanc. Pediat., 7, 297.

Siegenthaler, P., de Haller, J., de Haller, R., Hampaĩ, A., and Muller, A. F. (1964). Effect of experimental salt depletion and aldosterone load on sodium and chloride concentration in the sweat of patients with cystic fibrosis of the pancreas and of normal children. Arch. Dis. Childh., 39, 61. 